\title{
Historiografía de la criminalidad en América Latina. Una trayectoria de diálogos disciplinares y debates regionales*
}

\section{Hugo José Castro Valdebenito}

Docente e investigador del Departamento de Historia de la Universidad de Playa Ancha (Chile) y Director del programa de Postgrado en Gestión Cultural de la misma institución. Correo electrónico: hugo.castro@ upla.cl. El autor es magister en Relaciones Internacionales de la Pontificia Universidad Católica de Valparaíso (Chile) y Doctorando en Historia de la Universidad Santiago de Chile. Entre sus publicaciones recientes tenemos: "Criminalização e castigo na formação do estado-nação: a imprensa chilena durante a reforma do sistema prisional (1832 a 1850)" Revista Direito e Práxis Vol. 10 No. 1(2019) y “Modelos, tendencias y cotidianidades en los inicios de la cárcel penitenciaria de Santiago de Chile, 1843-1860" Diálogos: Revista electrónica de historia Vol. 19 No. 1 (2018). Entre sus temás de interés están: Historia de la Criminalidad y los sistemas de castigo; Historia política; Historia regional.

Recibido: 1 de agosto de 2018

Aprobado: 8 de marzo de 2019

Modificado: 18 de marzo de 2019

Artículo de investigación científica

DOI: http://dx.doi.org/10.15648/hc.35.2019.10

* $\quad$ Este artículo forma parte del proyecto de investigación Folio No 2018081301, titulado "Prisión política en Chile durante el s.XIX: Formas de Justicia política y castigo estatal "Financiado en concurso regular por la Dirección General de Investigación de la Universidad de Playa Ancha (Chile). Esta publicación está bajo una licencia Creative Commons Reconocimiento-NoComercial 4.0 
Historiografía de la criminalidad en América Latina. Una trayectoria de diálogos disciplinares y debates regionales

\title{
Resumen
}

El presente estudio reflexiona sobre la trayectoria que ha experimentado el campo de estudios historiográficos enfocados específicamente en el fenómeno de la criminalidad y la justicia penal en Latinoamérica. Para ello, se desarrolla un actualizado balance sobre los aportes más significativos en la articulación epistemológica de este campo de estudios desde la década de 1980 hasta la actualidad, considerando especialmente las líneas de investigación historiográfica que se han consolidado regionalmente y que han proyectado los diálogos disciplinares de este campo de estudio con las ciencias jurídicas y sociales.

Palabras clave: historiografía, criminalidad, debates disciplinares, justicias.

Historiography of Criminality in Latin America. A trajectory of disciplinary dialogues and regional debates

\begin{abstract}
Abstrac
The present study reflects on the trajectory of the field of historiographical studies focused specifically on the phenomenon of criminality and criminal justice in Latin America. For this, an updated balance is developed on the most significant contributions in the epistemological articulation of this field of studies from the 1980s to the present, considering especially the historiographic research lines that have been consolidated regionally and that have projected the disciplinary dialogues of this field I study with the legal and social sciences.
\end{abstract}

Keywords: historiography; criminality; disciplinary debates; justices.

Historiografia da criminalidade na América Latina. Uma trajetória de diálogos disciplinares e debates regionais

\section{Resumo}

O presente estudo reflete sobre a trajetória do campo dos estudos historiográficos voltados especificamente para o fenômeno da criminalidade e da justiça criminal na América Latina. Para isso, desenvolve-se um balanço atualizado sobre as contribuições mais 
significativas na articulação epistemológica deste campo de estudos a partir da década de 1980 até o presente, considerando especialmente as linhas de pesquisa historiográfica que se consolidaram regionalmente e que projetaram os diálogos disciplinares deste campo estudo com as ciências legais e sociais.

Palavras chave: historiografia, criminalidade, debates disciplinares, juízes

Historiographie de la criminalité en Amérique latine. Une trajectoire de dialogues disciplinaires et de débats régionaux

\section{Résumé}

La présente étude reflète la trajectoire du champ des études historiographiques axées spécifiquement sur le phénomène de la criminalité et de la justice pénale en Amérique latine. Pour cela, un bilan actualisé est développé sur les contributions les plus significatives dans l'articulation épistémologique de ce champ d'études des années 1980 à nos jours, en considérant notamment les axes de recherche historiographique qui ont été consolidés régionalement et qui ont projeté les dialogues disciplinaires de ce domaine j'étudie avec les sciences juridiques et sociales.

Mots-clés: historiographie; la criminalité les débats disciplinaires; les juges.

\section{INTRODUCCIÓN}

Los estudios historiográficos sobre los diversos fenómenos de la criminalidad y el sistema penitenciario son relativamente recientes, aun cuando los trabajos propiamente criminológicos y de derecho penal se remontan al siglo XVIII con estudios clásicos como los de Beccaria y su Tratado de los delitos y las penas ${ }^{1}$, o el Panopticon ${ }^{2}$ de Bentham. Este último trabajo, en particular, es un caso interesante dado que muestra el sentido de la evolución de las medidas correctivas del poder estatal en Europa y Estados Unidos, además de constituirse como uno de los modelos de trasferencia

1 Beccaria, Cesare. Tratado de los delitos y de las penas. en casa de Rosa, (Paris: Librero, 1828)

2 Bentham, Jeremy. Panopticon: or, The inspection-house. Containing the idea of a new principle of construction applicable to any sort of establishment, in which persons of any description are to be kept under inspection, etc. (Dublin: Thomas Byrne, 1791) 
arquitectónica y de apropiación epistemológica que más utilizado durante el siglo XIX en la institucionalización punitiva de los jóvenes Estados de América Latina.

Con el ingreso de la criminología positivista -y junto con ella la estadística criminal y la antropóloga criminal legada por Cesare Lombroso- la caracterización de lo criminal o de la locura, la enfermedad, la vagancia o la prostitución como "lo patológico", delimitó las pautas históricas del control social y el disciplinamiento de los individuos pertenecientes a las clases explotadas de la sociedad, fenómeno que llamó la atención de investigadores de diversas áreas del conocimiento que iniciaron una tradición de abordajes variopintos sobre las cuestiones vinculadas a la criminalidad y al desarrollo histórico de la justicia penal en Latinoamérica.

Para esclarecer los componentes y elementos que dieron forma a dicho interés historiográfico sobre la criminalidad en América Latina, el estudio se dividirá en tres áreas de análisis que serán utilizadas para explicar la trayectoria historiográfica de este campo de estudio desde la década de 1980 hasta la actualidad.

En primer lugar, daremos cuenta de algunas discusiones disciplinares generadas tras el ingreso de posturas y enfoques derivados desde la criminología crítica hacia el debate académico latinoamericano, tomando para ello el trabajo del español José Rico, publicado en 1977 bajo el titulo Crimen y justicia en América Latina, en tanto constituye una obra pionera al considerar el problema de la delincuencia y la justicia penal en el área geográfica de América Latina. En este mismo sentido, se consideran los trabajos de la criminóloga venezolana Rosa del Olmo y la brasileña Vera Malaguti, así como también las apropiaciones teóricas desde la criminología crítica italiana, principalmente desarrollada por los criminólogos y sociólogos marxistas, Massimo Pavarini y Dario Melossi.

En segundo lugar, el estudio se concentra sobre el desarrollo regional de 274 estudios historiográficos sobre la cuestión criminal; sistemas de prisiones, delincuencia urbana, policías, jueces y sistemas judiciales, etcétera. Este punto se justifica al identificar y considerar los diversos aportes historio- 
gráficos provenientes principalmente de Estados Unidos, México, Argentina y Chile, a través de abordajes compilatorios sobre la criminalidad en latinoamerica. Se espera dar luces del viraje que los historiadores latinoamericanos de la "cuestión criminal" han dado hacia la antropología histórica, alejándose en parte de los consensos epistemológicos con el derecho y la sociología juridica. Adoptando nuevas interpretaciones y distintas maneras de interpelar al pasado en su relación con la criminalidad y el castigo estatal.

El ultimo apartado de este trabajo, se esfuerza por situar los diversos centros de producción historiográfica en América Latina en torno a los diferentes topicos asociados a la criminalidad, sus investigadores, la orientación de los proyectos y las revistas especializadas sobre la tematica. Todo esto a fin de dar cuenta del estado de avance y consolidación de este campo de estudios a escala regional.

Finalmente, se concluye este estudio con una reflexión que involucra una valoración acerca de la trayectoria de la historiografía latinoameiricana sobre la criminalidad destacando los aportes disciplinares más relevantes y proyectándolos en una periodización que ubica las discusiones y debates historiográficos que nos parecen más relevantes para entender y explicar la trayectoria historiográfica de los estudios latinoamericanos sobre la criminalidad.

\section{Primeros acercamientos al estudio de la criminalidad en Amé- RICA LATINA}

En la presentación de la quinta edición de Crimen y Justicia en América Latina en 1997, la Editorial Siglo XXI invitó a José María Rico -abogado español especialista en criminología y esposo de la ex presidenta de Costa Rica Laura Chinchilla-, para que hiciera un recuento de las reflexiones surgidas en su quehacer profesional desde la primera edición -en 1977- de su libro Crimen y Justicia en América ${ }^{3}$. José Rico, en la presentación del texto recordaba que dicho estudio fue el primer intento por analizar de

3 Rico, José M. Crimen y justicia en América Latina. (México: Siglo XXI, 1ra ed., 1977) 
manera conjunta el fenómeno de la criminalidad y su relación con la justicia penal en América Latina ${ }^{4}$. Especialmente, considerando las coyunturas históricas surgidas en un contexto de gran conflictividad y violencia en América Latina desde el cual José Rico abordaba la temática de la criminalidad considerando en su estudio a gran parte de los países de la región. Los autoritarismos, dictaduras militares, la Guerra Fría, las guerrillas y los estados de excepción en América Latina fueron el telón de fondo de su visión de conjunto. El libro no escondía la intencionalidad con la que fue escrito: "denunciar los modelos de control social usados por las dictaduras y defender el estado de derecho junto a las garantías individuales de los ciudadanos, proyectando un sistema de justicia accesible, independiente y aplicado"5. La obra permaneció prohibida en Argentina, Chile y Guatemala hasta la tercera edición. Es notable, sin embargo, que aunque el contexto latinoamericano deambulaba por discusión de mayor dogmatismo y tensiones partidistas, el libro tuvo una muy buena acogida en los círculos académicos. En definitiva, el libro de José Rico, entre el año 1977 y hasta 1998, se editó 5 veces ${ }^{6}$.

La obra no obstante, no fue un esfuerzo realizado en solitario por el autor, sino más bien la canalización de los resultados del convenio entre el Grupo Latinoamericano de Criminología Comparada del Instituto de Criminología de la Universidad del Zulia en Venezuela y el Centro Internacional de Criminología Comparada de la Universidad de Montreal en Canadá, donde se encontraba adscrito el autor. En la conclusión de la presentación de la nueva edición, el autor se cuestionaba que tras dos décadas de circulación de su propuesta aun existiera tan poca correlación entre el avance teórico que implicó dicho trabajo para la región y la ejecución de acciones concretas por parte de las sociedades latinoamericanas, "que hubieran permitido aportar soluciones a las graves y permanentes deficiencias observadas en el sector"’. La pregunta que puede surgir hasta aquí es; ¿cuál

4 Rico, José M. Justicia penal y transición democrática en América Latina. (México: Siglo XXI, 5ta ed.,1997), 12.

2765 Rico, José M. Crimen y justicia, 23.

6 Melo Flórez, Jairo. "Apuntes sobre la historiografía del crimen y la justicia penal de América Latina". Historia, crimen y justicia, (2015), https://hccj.hypotheses.org/2

7 Rico, José M. Justicia penal y transición democrática en América Latina (México: Siglo XXI, 5ta ed. 1997), 11-12. 
es el objeto de iniciar un balance historiográfico sobre la criminalidad en América Latina comenzando por un estudio de criminología? La verdad es que, aunque es cierto que José Rico no es historiador, ni que su trabajo haya sido propiamente una investigación histórica, dado que su intencionalidad no estaba vinculada a recrear el pasado sino que, básicamente, a interpelar el pasado para abordar cuestiones y problemáticas del presente del castigo estatal dictatorial latinoamericano. Su libro, es uno de los trabajos pioneros sobre el fenómeno de la criminalidad en perspectiva regional y comparada en América Latina. Su estudio presenta varias aproximaciones a la historia. Por un lado, y desde el punto de vista de la construcción de una explicación a largo plazo, utiliza el pasado para retrotraer y situar las complejidades historicás en los experimentos de implementación de los sistemas punitivos de control estatal en Latinoamérica. Por otro lado, su visión de conjunto sobre la cual observa la trayectoria de la justicia penal y la criminalidad en los diferentes estados latinoamericanos denota una concepción histórica sobre América Latina, adoptada - al parecer- del argentino Halperin Donghi, por la cual Latinoamérica se constituye como región principalmente por su relación generalmente tensa con los países de Europa y Norteamérica: "El factor unificador es exterior; está constituido por la amenaza constante de las potencias extranjeras, así como por la hostilidad general del pueblo latinoamericano hacia éstas"s.

Las aportaciones para la historiografía de la criminalidad en América Latina están sujetas al debate que generó el mencionado libro desde su publicación en 1977, pero no solo por lo controversial de la denuncia histórica de José Rico, sino por su capacidad de comprender y estudiar el fenómeno de la criminalidad en América Latina desde una visión de conjunto, lo que permitió observar las experiencias nacionales desde una óptica regional y en perspectiva histórica comparada. Dando inicio así, a una fuerte producción académica de estudios comparados, en Centroamérica principalmente.

Un par de años después de la publicación de Crimen y Justicia en América, la criminóloga marxista e historiadora venezolana Rosa del Olmo

8 Rico, José M. Crimen y justicia, 24. 
publicó la investigación titulada América Latina y su criminología ${ }^{9}$. Esta obra es considerada el primer estudio historiográfico sobre las trasferencias y flujos de ideas criminológicas desde Europa hacia América Latina. Esta vez se trata de un esfuerzo de investigación que se preocupó de conocer los canales de difusión de la teoría criminológica italiana en Latinoamérica, utilizando apropiaciones y adaptaciones teóricas más estructurales. Al igual que José Rico, su estudio consideró un rastreo comparado país por país de la región, comprendiendo el fenómeno de manera regional. Sin embargo, la metodología para recoger la información fue diferente. Puesto que la autora recurrió a la cooperación académica internacional enviando más de un centenar de formularios a distintos especialistas criminólogos, abogados e historiadores de los países de la región. Lo que recibió al final, lo utilizó para constituir un corpus de información especializada sobre el fenómeno de la criminalidad América Latina; bibliografía, revistas académicas, centros de estudios, congresos y materiales de pesquisa sobre la criminalidad y los sistemas punitivos en América Latina, etc. Paradójicamente lo que llevó a la autora a realizar una historia general de la criminología en América Latina fue la gran cantidad de información que pudo recopilar, lo que a fin de cuentas le permitió llevar a cabo su objetivo original; una bistoria de la criminología país por país ${ }^{10}$. Al parecer el libro demostró una similar acogida que la obra de Rico, pues en 1999 ya había sido editada 4 veces, también por Siglo $\mathrm{XXI}^{11}$.

Del Olmo encuentra una relación estrecha entre la criminología y el desarrollo del capitalismo en Europa y América, en especial respecto a los procesos de acumulación originaria en América Latina y el control de las élites dominantes sobre las clases populares. La criminología para la autora sería el "justificativo racional" para disciplinar a los ciudadanos, específicamente a los que ofrecieran resistencia a la moral y al sistema productivo. Los canales de difusión de la "ideología de criminalización” serían -según la autora- los congresos científicos y las organizaciones internacionales que fueron impuestos a América Latina desde los Estados Unidos ${ }^{12}$.

12 Del Olmo, Rosa, América Latina y su criminología, 248-250. 
Conviene señalar que durante este primer período de estudios sobre la criminalidad en América Latina se ven también muy presentes las influencias de los trabajos del marxista italiano Massimo Pavarini, espacialmente a través de la obra Control y dominación. Teorías criminológicas burguesas y proyecto begemónico ${ }^{13}$ que además de tener una amplia circulación en México y Argentina, aportando un cuerpo teórico de interpretación critica para los estudios sobre los sistemas de control y castigo estatal y la historia de la incorporación de dichos sistemas a la estructura del Estado liberal en los siglos XIX y XX. Junto con esta obra, y en esa misma línea pero en coautoría con Dario Melossi, publicaron Cárcel y fabrica. Orígenes del sistema penitenciario ${ }^{14}$, que a diferencia de la famosa obra de Michel Foucault Vigilar y Castigar. Nacimiento de la prisión ${ }^{15}$, considera la intencionalidad del sistema capitalista en la trasformación del castigo corporal al castigo de encierro como instrumento de control de las clases trabajadoras. Para muchos historiadores de la criminalidad, incluyendo a la argentina Lila Caimari, la obra de Foucault, marca un antes y un después en la historia de los sistemas de castigo social ${ }^{16}$.

La investigación histórica de la criminalidad ha seguido los derroteros de dicha monografía de Foucault, ampliándola, rectificándola y asumiéndola como un modelo necesario para iniciar cualquier estudio que tuviese directa o indirecta relación con el estudio de los mecanismos de poder que se encuentran detrás de las reglamentaciones y los actos de los gobernantes.

En este sentido, investigadores europeos y norteamericanos se encargaron de profundizar y matizar los diversos aspectos de la institución carcelaria, apreciando las transformaciones en el ámbito de la justicia penal, los cambios en las ideologías reinantes o simplemente los aspectos de la vida cotidiana de los recintos carcelarios. En gran medida este renovado interés de los historiadores se encuentra motivado por el desplazamiento de

13 Pavarini, Massimo. Control y dominación: teorías criminológicas burguesas y proyecto hegemónico. (México: Siglo XXI, 1983)

14 Melossi, Dario; Pavarini, Massimo. Cárcel y fábrica: los orígenes del sistema penitenciario (siglos XVI-XIX). (México: Siglo XXI, 1985)

15 Foucault, Michel. Vigilar y castigar: nacimiento de la prisión. (Buenos Aires: Siglo XXI, 1975)

16 Caimari, Lila. Apenas un delincuente. Crimen, cultura y castigo en la Argentina. (Buenos Aires: Siglo XXI, 2012), 37 
sus análisis desde las élites hacia la gente común, cuestión no menor en la epistemología de este campo de estudios.

No obstante, los esfuerzos interpretativos de la criminología critica italiana, formularon un área de abordaje historiográfico diferente a la subjetividades e imaginarios del castigo foucaultiano. Este abordaje vinculado a la crítica capitalista, al parecer promovió una importante producción intelectual durante la década de 1990, especialmente en los estudios de los historiadores argentinos del derecho penal Roberto Gargarella ${ }^{17}$, Raul Zaffaroni $^{18}$, Roberto Bergalli ${ }^{19}$ y Máximo Sozzo ${ }^{20}$.

Un interés similar se despertó en numerosos investigadores de América Latina durante la década de 1980 y 1990, aunque con algunos estudios anteriores, en gran medida inspirados por las líneas teóricas y metodológicas ya señaladas y por las propias experiencias regionales del continente, que marcaron la trayectoria política, económica, social y penal de diferentes naciones de América Latina ${ }^{21}$.

Como hemos visto, el primer período de desarrollo de los estudios historiográficos sobre la criminalidad y la justicia penal en perspectiva Latinoamérica, se desarrolló principalmente desde aportaciones derivadas de los estudios criminológicos y sociológicos que utilizando la historia como disciplina auxiliar desarrollaron explicaciones en perspectiva regional y a

17 Ver Gargarella, Roberto. Los fundamentos legales de la desigualdad: el constitucionalismo en América (1776-1860). (Madrid: Siglo XXI, 2005)

18 Vea Zaffaroni, Eugenio Raúl. Sistemas penales y derechos humanos en América Latina: documento final del programa de investigación. Informe final. (Buenos Aires: Ediciones Depalma, 1986)

19 Ver Bergalli, Roberto, et al. Control social punitivo. Sistema penal e instancias de aplicación (policía, jurisdicción y cárcel), Barcelona: Bosch, 1996)

20 Ver Sozzo, Máximo. Policía, violencia, democracia: ensayos sociológicos. (Santa Fe: U.Nac. del Litoral, 2005)

21 Algunas investigaciones relevantes en este sentido son; Aufderheide, Patricia. Order and Violence: Social Deviance and Social Control in Brazil (1780-1840), (Ph.D. dissertation, University of Minnesota, Minneapolis, 1976); Rohlfes, Laurence John. Police and Penal Correction in Mexico City, 18761911: A Study of Order and Progress in Porfirian Mexico. 1984. (Dissertation, Tulane University, New Orleans, 1983); Fausto, Boris. Crime e cotidiano: a criminalidade em São Paulo, 1880-1924. (Sao Paulo: Edusp, 1984); Aguirre, Carlos; Walker, Charles (ed.). Bandoleros, abigeos y montoneros: criminalidad y violencia en el Perú, siglos XVIII-XX. (Lima: Instituto de Apoyo Agrario, 1990); PICÓ, Fernando. El día menos pensado: historia de los presidiarios en Puerto Rico, 1793-1993. (San Juan: Ediciones Huracán, 1994) 
través de un método comparado. Estas investigaciones, principalmente provenientes de la ciencias jurídicas, posicionaron el fenómeno de la criminalidad extrayéndolo de sus contextos nacionales de estudios fragmentados y abrieron el campo a nuevas proyecciones para abordar una larga lista de fenómenos internos de la denominada "cuestión criminal", que marcaron el siguiente período de desarrollo de la trayectoria historiográfica de los estudios sobre criminalidad.

Más que una mera aplicación de modelos historiográficos extranjeros a la realidad penal de nuestro continente, en los últimos años se han hecho esfuerzos para investigar con seriedad y con documentación inédita las particularidades del fenómeno de la criminalidad de cada país, aunque todavía existe necesidad de estudiar mayores temáticas. Esta es al menos la conclusión que se desprende en The birth of the penitentiary in Latin America: essays on criminology, prison reform, and social control, 1830$1940^{22}$, trabajo editado por Ricardo Salvatore y Carlos Aguirre en 1996, el cual busca entregar un estado de la cuestión sobre la materia y aportar nuevos acercamientos a la penalidad latinoamericana ${ }^{23}$.

\section{LA HISTORIA DE LA CRIMINALIDAD COMO CAMPO DE ESTUdIO EN LATI- NOAMÉRICA}

Al finalizar la década de los noventas, la historia de la criminalidad había tomado una dirección muy diferente a la que dio origen a las propuestas de José Rico y Rosa del Olmo. La orientación de los trabajos y estudios historiográficos -que como hemos señalado, aumentaron considerablemente desde la década de 1990- pasaron de la mera comprensión del fenómeno de la criminalidad y las tensiones con el sistema jurídico y punitivo estatal a un análisis social de la criminalidad. Se abandona en parte el préstamo metodológico que hizo la historiografía al derecho y la criminología, y se comienza un fructífero dialogo con la sociología y la historia social. Sin embargo, aun en estos años la historia de la criminalidad no es un área de

22 Salvatore, Ricardo D.; Aguirre, Carlos (ed.). The birth of the penitentiary in Latin America: essays on criminology, prison reform, and social control, 1830-1940.(Texas: University of Texas Press, 1996)

23 Salvatore, Ricardo D.; Aguirre, Carlos (ed.). The birth of the penitentiary in Latin America, 43. 
estudio consolidada sino más bien una derivación de estudios relacionados con la historia social, de género, cultural, de la violencia y del derecho. Esta es una situación reconocida porque tal como asegura Lila Caimari, en un recuento retrospectivo publicado en 2016, "los historiadores de la cuestión criminal son al mismo tiempo historiadores sociales, políticos, económicos y culturales"24.

Durante esta década, el argentino Ricardo D. Salvatore, señalaría que la historia de la criminalidad seria en aquellos días "un campo de investigación abierto pero disperso en diferentes temas: estudio de bandidos, prostitución, violencia callejera, policía, prisiones, castigo corporal, ideologías de ordenamiento social, litigios judiciales de indígenas, abogados y prácticas jurídicas" 25 .

Estos abordajes al pasado se enfocaron principalmente en reconstruir la historia de la criminalidad a escalas nacionales, y en una medida importante fueron proyectados por un auge de nuevos enfoques como los estudios de género, los estudios subalternos o la historia desde abajo, el análisis del discurso, las etnografías de la modernidad, la historia de las ciencias, investigaciones sobre hegemonía y orden social en la construcción de los estados, entre otros.

Ricardo Salvatore identificó como fuentes teóricas de esta área promisoria los trabajos de Michel Foucault, E. P. Thompson, Eric J. Hobsbawm, Joan Scott, Charles Tilly, Norbert Elias, James C. Scott y Jürgen Habermas, los cuales según el autor "estimularon a los historiadores a mirar en los archivos judiciales y de la policía para responder a una variedad de problemas vinculados a la dimensión social de la criminalidad" ${ }^{26}$. No obstante, para 1996 los estudios historiográficos sobre criminalidad en América Latina apenas estaban en términos de aproximaciones y todavía no se daba el paso para abordar la historia de la criminalidad y la justicia

24 Caimari, Lila. "Los historiadores y la "cuestión criminal" en América Latina. Notas para un estado de la cuestión”. Revista de Prisiones, No2, (2016), 5.

25 Salvatore, Ricardo D. "Criminal justice history in Latin America: promising notes". Crime, Histoire \& Sociétés/Crime, History \& Societies, vol. 2, no 2, (1998), 7.

26 Salvatore, Ricardo D. "Criminal justice history in Latin America", 9. 
penal desde una perspectiva regional. En dicho año, se publica The Birth of the Penitentiary in Latin America, -estudio antes señalado- realizado por Salvatore y Carlos Aguirre. Este trabajo marca un antes y después en la forma de entender la criminalidad desde un ángulo completamente historiográfico, utilizando las disciplinas como el derecho, la criminología y la sociología como ciencias auxiliares para el trabajo historiográfico. Veinte años después de la publicación de la obra, los autores volvieron a retomar la pregunta que dirigió la investigación: ¿Cómo y por qué los países de la región adoptaron modelos punitivos foráneos para el control de las clases populares durante el período pos independentista ${ }^{27}$. No cabe duda que las preguntas e interrogantes que llevaron a los historiadores a mirar el pasado de los sistemas de castigo en las construcciones del Estado-nación, han sido una de las líneas de mayor desarrollo en los historiadores nacionales. Carlos Aguirre en el reconocido articulo Cárcel y sociedad en América Latina: 1800-1940, realiza una afirmación que grafica el estado de depuración en que se encontraba el campo de estudio sobre los sistemas de prisiones en América Latina en los años noventa. Aguirre afirma que

“...construir la historia de las prisiones en América Latina moderna no es una tarea fácil, pues ella deberá abarcar varios países que han seguido diferentes trayectorias socio-políticas y distintos patrones de desarrollo económico, poseen diversas estructuras étnico-raciales y han aplicado variados experimentos con el castigo y el encarcelamiento. Estos últimos, a su vez, son el resultado de las diferencias en la adaptación de doctrinas extranjeras, en el desarrollo de debates ideológicos y políticos y en las formas subalternas de acción y resistencia"28.

El fin de la década de los noventas y principios de los años dos mil fue el escenario de impulso de varios historiadores que se interesaron por las manifestaciones sociales y políticas de la criminalidad. La obra de Eric Hobsbawm Bandidos sirvió de modelo interpretativo para la construcción

27 Salvatore, Ricardo D.; Aguirre, Carlos. Revisitando El nacimiento de la penitenciaría en América Latina veinte años después. Revista de Prisiones, Nº4, (2017), 12

28 Aguirre, Carlos. "Cárcel y sociedad en América Latina". Historia social urbana: Espacios y flujos, en Ed. Eduardo Kingman, (2009), 210. 
de categorías históricas suficientes para la historia de la dimensión social del bandolerismo, el bandidaje rural, el vagabundaje o la delincuencia urbana, entre otros fenómenos de la mal denominada "anormalidad". Ejemplo de ello, y sin ir más lejos, es el libro de Ivette Lozoya sobre Delincuentes, bandoleros y montoneros. Violencia social en el espacio rural chileno (1850-1870) ${ }^{29}$ donde la búsqueda de la dimensión social de los bandidos rurales responde a una apropiación declarada por parte de la autora a la categoría histórica trabajada por Hobsbawm.

De todos modos, es importante hacer presente que las interpretaciones de Hobsbawm sobre el bandidaje escapan a la incuestionable aplicabilidad en la realidad latinoamericana, pues los plantea como bandidos "tipo", aplicando a los modelos de criminalidad rural un estilo delictual idealizado. Tal es el caso de la citada obra Bandidos, donde categoriza a los bandidos como criminales "utilitarios", exponiendo el caso de Robin Hood y su repetitividad global ${ }^{30}$.

En definitiva, la mayor parte de las aportaciones que estamos reseñando provienen de corrientes y enfoques historiográficos foráneos que fueron apropiados en diversos países latinoamericanos en la década de los años dos mil, aumentado considerablemente -como hemos dicho- los abordajes a la temática desde la historiografía regional.

En Chile, por ejemplo, los trabajos más directamente vinculados al estudio de fenómenos de la criminalidad y la justicia penal en perspectiva histórica son los iniciados por Marco Antonio León León en la última parte de la década de 1990. La investigación doctoral de León realizada en la Pontificia Universidad Católica de Chile titulada Encierro y corrección. La configuración de un sistema de prisiones en Chile, (1800-1911) ${ }^{31}$ es sin duda el esfuerzo investigativo más extenso y detallado sobre la evolución del

29 Lozoya, Ivette. Delincuentes, bandoleros y montoneros: Violencia social en el espacio rural chileno (1850-1870). (Santiago: LOM Ediciones, 2014)

$28430 \quad$ Lozoya, Ivette. Delincuentes, bandoleros y montoneros, 19

31 Publicada por la Universidad Central de Chile: LEÓN, Marco Antonio León. Encierro y corrección: la configuración de un sistema de prisiones en Chile: 1800-1911. (Santiago: Universidad Central de Chile, Facultad de Ciencias Jurídicas y Sociales, 2003). 
sistema de prisiones en Chile. León, quien declara desarrollar una perspectiva historiográfica social de la prisión, considera en su esquema no solo las relaciones institucionales del castigo estatal, si no también dar cuanta de variados elementos en constante tensión social. Este tipo de estudios sigue la línea de estudios nacionales y centralizados que señalábamos anteriormente, es decir constituye esfuerzo por reconocer el pasado de articulación de la política criminal en los países de América Latina en los períodos post independencias, específicamente en las explicaciones sobre la construcción del Estado. También destacan los aportes de Marcos Fernández Labbe ${ }^{32}$ y su estudio sobre los presidios rurales y los imaginarios del castigo penal; sobre bandolerismo con Ivette Lozoya ${ }^{33}$; sobre sistemas judiciales con María José Correa; o bien, sobre las policías y ladrones recreados en los trabajos de Daniel Palma. También los estudios judiciales y notariales con Aude Argouse ${ }^{34}$ y María Eugenia Albornoz ${ }^{35}$ o sobre los jueces con los estudios de Víctor Brangier, entre otros, sobresalen por sus aportaciones. Quizá los trabajos sobre las experiencias nacionales sean los más prolíferos en Chile, aunque se mantienen una limitada producción sobre la temática en términos comparativos con respecto a México y Argentina.

Por otro lado, los estudios historiográficos sobre el control y el disciplinamiento estatal en perspectiva comparada son aún más escasos y recientes. Mención especial al medianamente reciente (2015) texto de Julio Pinto y Daniel Palma et al titulado El orden y el bajo pueblo. Los regímenes de Portales y rosas frente al mundo popular, 1829-1952 ${ }^{36}$. El texto utiliza las

32 Ver aportes en Fernández Labbé, Marcos. Prisión común, imaginario social e identidad: Chile, 18701920. (Santiago: Dirección de Biblioteca Archivos y Museos, 2003); y en Fernández Labbé, Marcos. "Relatos de precariedad y encierro: la cárcel rural en el Chile de la segunda mitad del siglo XIX". Contribuciones científicas y tecnológicas, vol. 26, (1998),118.

33 Lozoya, Ivette. Delincuentes, bandoleros y montoneros: Violencia social en el espacio rural chileno (1850-1870). (Santiago: LOM Ediciones, 2014)

34 Argouse, Aude. "Prueba, información y papeles. Hacia una plena inclusión del escribano y de sus agencias en la historia de la justicia en Hispanoamérica (Chile, siglos XVII-XVIII)". Revista Historia y Justicia, no 8, (2017), 97-137.

35 Albornoz Vásquez, María Eugenia "Seguir un delito a lo largo del tiempo: Interrogaciones al cuerpo documental de pleitos judiciales por injuria en Chile, Siglos XVIII y XIX.” Revista de Historia Social y de las Mentalidades, Vol. 10. N² (2006): 195-226.

36 Vallejos, Julio Pinto, et al. El orden y el bajo pueblo: los regímenes de Portales y Rosas frente al mundo popular, 1829-1852. (Santiago: LOM Ediciones, 2015). 
experiencias "ordenadoras" de Chile -con el régimen de Portales- y Argentina -con Rosas- para hacer los contrapuntos en las relaciones y prácticas de las élites criollas chilenas y argentinas en las primeras décadas de formación del Estado, donde la criminalización de los actores populares fue bastante fuerte por parte del levantamiento de discursos prejuiciosos desde la clase dominante, criminalizando y estigmatizando a los sujetos populares, sobre todo luego de la reforma al sistema de prisiones y castigos, y frente a la inauguración y promoción del sistema penitenciario en la década de $1840^{37}$.

Sin embargo, los intentos más concretos para presentar una historia del crimen y la justicia penal de América Latina han surgido desde Estados Unidos e Inglaterra en la forma de compilaciones coordinadas y publicadas en inglés. Destacan los nombres del historiador peruano Carlos A. Aguirre, adscrito a la Universidad de Oregon y Ricardo Salvatore a quienes ya hemos mencionamos anteriormente. Ambos, en la década de 1990, coordinaron dos compilaciones de congresos sobre crimen y sociedad y delito y Estado. Luego desarrollaron una tercera reunión que fue publicada por la Universidad de Guadalajara en el año 2010 como resultado de un congreso llevado a cabo en la ciudad de Chillán, y la más reciente, la cuarta compilación, del año 2013, es producto de un acercamiento a interpretaciones teóricas de mayor dimensión, específicamente el proceso civilizatorio de Norbert Elias ${ }^{38}$.

La primera de las compilación que señalamos, llevo el título de Reconstructing Criminality in Latin America ${ }^{39}$, editada por Aguirre y Robert Buffington. En la introducción, a cargo de Buffington, se conceptualiza el significado de criminalidad en América Latina. Aclara que la criminalidad es un concepto histórico que por ende se debe estudiar acorde con su contexto, de tal manera que la reconstrucción de la historia del crimen en América Latina conlleva aproximarse "a la manera cómo diferentes so-

37 Hemos estudiado este período en Castro Valdebenito, Hugo Jose, Sánchez, Alessandro Monteverde;; Saavedra, Juan. "Modelos, tendencias y cotidianidades en los inicios de la cárcel penitenciaria de Santiago de Chile, 1843-1860”. Diálogos: Revista electrónica de historia, vol. 19, no 1,(2018), 69-101.

38 Elias, Norbert. El proceso civilizatorio. (Rio de Janeiro: Jorge Zahar, 1990)

39 Aguirre, Carlos A.; BUFFINGTON, Robert (ed.). Reconstructing Criminality in Latin America. (Rowman \& Littlefield Publishers, 2001) 
ciedades de América Latina, en diversos tiempos con sus respectivas historias, vieron, describieron, definieron y reaccionaron al comportamiento 'criminal'"

Uno de los problemas con los que se enfrentaron para la realización de la compilación es que aunque el ámbito es América Latina el peso de la producción, como señalábamos al inicio del texto, se concentra en México y Argentina. De los diez artículos que componen la compilación cuatro están dedicados a México, tres a Argentina y los restantes a Perú, Brasil y Colombia; pero incluso esto también debe ser matizado puesto que en realidad las investigaciones se enfocan en la Ciudad de México, Buenos Aires, Arequipa, Río de Janeiro y Medellín ${ }^{41}$. A lo anterior se suma la dificultad de una periodización que converja con las evidentes diferencias regionales de cada caso, algo que Buffington sortea afirmando que es posible entender la criminalidad latinoamericana si se superponen los procesos de control social y criminalidad de Europa Occidental y Estados Unidos bajo el supuesto de una relación conectada por las relaciones coloniales y neocoloniales ${ }^{42}$.

El planteamiento de Buffington lo lleva a considerar los procesos de tecnificación del castigo y el control social aplicados en Europa apoyando las teorías de Michel Foucault, Jürgen Habermas, Benedict Anderson y E. P. Thompson, y afirma que si bien América Latina desde su independencia estuvo a la zaga de Europa, las élites latinoamericanas se esforzaron por adoptar los modelos de control y represión importados desde Europa ${ }^{43}$.

Para Buffington, la historia de la criminalidad en América Latina debería observarse "a través del lente de la modernización, por ello los ensayos de la compilación toman un contexto general de aumento y fortalecimiento del Estado centralizado y tecnocrático para analizar la criminalidad de los negros, las mujeres, los vendedores ambulantes, las prostitutas, los disidentes políticos y las bandas de narcotraficantes" ${ }^{44}$.

40 Buffington Robert, Introduction: Conceptualizing Criminality in Latin America,11.

41 Melo Flórez, Jairo. "Apuntes sobre la historiografía”, 6.

42 Buffington Robert, Introduction: Conceptualizing Criminality in Latin America,12.

43 Buffington Robert, Introduction: Conceptualizing Criminality in Latin America, 15.

44 Buffington Robert, Introduction: Conceptualizing Criminality in Latin America, 18. 
Poco tiempo después fue publicado Crime and Punishment in Latin America ${ }^{45}$, una compilación editada esta vez por Ricardo Salvatore, Carlos Aguirre y Gilbert M. Joseph, este último director del Instituto de Estudios Latinoamericanos e Ibéricos en la Universidad de Yale ${ }^{46}$. La contraportada de la edición indica que esta compilación es la "culminación de una década de esfuerzos innovadores en los estudios históricos de la ley y de fenómeno legal en la región". Sin embargo, el enfoque de esta recopilación está mucho más centrada en los estudios jurídicos, de hecho se divide en mediaciones legales - interacciones entre justicia y sociedad, la construcción social y cultural de la prisión ${ }^{47}$.

En comparación con la compilación precedente, Crime and Punishment presenta un cuerpo de trabajos más robusto, centrados en la historia social y cultural, y donde se comparten además, algunos acercamientos teóricos, especialmente en los trabajos relacionados con la historia de la prisión ${ }^{48}$.

Los editores de la publicación cuidaron más de convocar historiadores especialistas en la historia social del derecho antes que en abarcar una serie de ejemplos nacionales. La concentración de trabajos de México y Argentina es evidente en esta compilación, pero los editores parten de la hipótesis de un sistema legal compartido en la mayoría de países de América Latina desde su independencia en el que predomina la arbitrariedad y la aplicación diferenciada de la justicia ${ }^{49}$.

Siguiendo la hipótesis planteada por los editores de la compilación, la periodización ya no es un problema. El período de tiempo predominante en los ensayos recopilados está entre 1890 y 1930, sólo el trabajo de Char-

45 Salvatore Ricardo D., Aguirre Carlos, y JOSEPH Gilbert M., eds., Crime and punishment in Latin America: law and society since late colonial times, (Duke University Press, 2001)

46 Melo Flórez, Jairo. Apuntes sobre la historiografía, 8.

47 Salvatore Ricardo D., Aguirre Carlos, y Joseph Gilbert M., eds., Crime and punishment in Latin America, 21.

48 Salvatore Ricardo D., Aguirre Carlos, y Joseph Gilbert M., eds., Crime and punishment in Latin America, 11.

49 Aguirre Carlos y Salvatore Ricardo D., "Writing the History of Law, Crime, and Punishment in Latin America”, en Crime and punishment in Latin America: law and society since late colonial times, ed. Ricardo Donato Salvatore, Carlos Aguirre, y Eric A. Johnson, (Duke University Press, 2001), 15. 
les F. Walker acerca de las relaciones entre los indígenas y los tribunales coloniales en el Perú después de la rebelión de Tupac Amaru se aparta significativamente de ese marco temporal ${ }^{50}$. No es casualidad que sea esta la temporalidad "elegida" por los colaboradores, pues fue en este período cuando existió un interés de las élites en América Latina por aplicar innovaciones en sus sistemas judiciales con el fin de lograr el control del comportamiento de sus ciudadanos, y fue en estos años cuando las teorías del positivismo criminológico, la medicina legal - antropología criminal- y el darwinismo social se convirtieron en lo más innovador para conseguir el orden social. Es en esta época también, cuando el racionalismo jurídico tuvo que enfrentarse con más fuerza a las pasiones, el honor, las creencias y los rituales, interpretados por los juristas y médicos muchas veces como desviaciones o simplemente rezagos de épocas bárbaras en la que reinaba el oscurantismo.

El ensayo final de la compilación estuvo a cargo de Douglas $\mathrm{Hay}^{51}$, reconocido entre otras cosas por haber publicado junto con E. P. Thompson y otros, el libro colectivo titulado Albion's Fatal Tree en $1975^{52}$. Douglas Hay, aceptó desconocer el contexto latinoamericano al momento de hacer el texto, comparando los argumentos de los diferentes ensayos para a su vez contrastarlos con el contexto canadiense y europeo. El problema de la comparación de Douglas Hay radica - a nuestro entender- en que intenta confrontar dos tradiciones jurídicas totalmente diferentes, pero eso también ratifica que las particularidades del sistema judicial hispano que como tradición jurídica se estableció en América Latina es la base común sobre la cual posteriormente se desarrolló el derecho nacional de los Estados latinoamericanos, teniendo en común la adopción del sistema francés de codificación y sólo posteriormente, un inicio de procedimientos judiciales que se sustentaban en el positivismo criminológico italiano ${ }^{53}$.

50 Walker Charles F. en Crime and punishment in Latin America: law and society since late colonial times, ed. Ricardo Donato Salvatore, Carlos Aguirre, y Eric A. Johnson, (Duke University Press, 2001),176

51 Hay Douglas., "Law and Society in Comparative Perspective", en Crime and punishment in Latin America: law and society since late colonial times, ed. Ricardo Donato Salvatore, Carlos Aguirre, y Gilbert M. Joseph (Duke University Press, 2001), 418

52 Linebaugh, Peter, et al. Albion's fatal tree: crime and society in eighteenth-century (London: Allen Lane, 1975)

53 Hay Douglas., "Law and Society in Comparative Perspective", en Crime and punishment in Latin 
La primera de las compilaciones publicadas en español, fue el trabajo sobre Historia del crimen y la justicia en América Latina, coordinado por el mexicano Jorge Trujillo Bretón de la Universidad de Guadalajara ${ }^{54}$. La presentación fue escrita por Ricardo D. Salvatore, y en ésta, Salvatore realiza un balance crítico sobre el progreso de la historia de la justicia criminal en América Latina durante las dos décadas precedentes. Salvatore identifica dos vertientes principales: una, asociada con los trabajos de Thompson y Foucault y otra que se viene abriendo campo que adopta la teoría del "proceso civilizatorio" de Norbert Elias, las cuales les han permitido a los historiadores de "nueva generación" "el desplazamiento del centro de interés histórico hacia cuestiones de agencia, mentalidades, representaciones, opinión pública y, en general, aspectos de la 'cultura' que requieren formas de abordaje propios de la crítica literaria y de la antropología" 55 .

Son cinco los temas que se tratan en esta compilación: los vicios y el control social, los bandidos, las "violencias graves" (homicidios, riñas y estupro), los delitos y el castigo penitenciario o castigo estatal. Este estudio rompe con la tendencia de los estudios de caso anteriores vinculadas mayormente a las realidades mexicanas y argentinas, en cambio se incluyen tres trabajos chilenos: el de Marco Antonio León León, titulado "Perfilando una "degeneración” y una "regeneración": discursos y actitudes hacia el mundo popular en Chile durante el siglo XIX”; el de Marcos Fernández Labbé sobre la criminalización de las costumbres en el período finisecular, y el de Mauricio F. Rojas, sobre las pendencias decimonónicas ${ }^{56}$. Cabe destacar que estos estudios compilados no se limitaron al abordaje de problemas de las ciudades capitales de sus países como en las compila-

America: law and society since late colonial times, ed. Ricardo Donato Salvatore, Carlos Aguirre, y Gilbert M. Joseph (Duke University Press, 2001), 422.

54 Trujillo Breton, Jorge Alberto, et al. En la encrucijada: historia, marginalidad y delito en America Latina y los Estados Unidos de Norteamerica (siglos XIX y XX). (Guadalajara:Universidad de Guadalajara, 2010)

55 Salvatore Ricardo D., "De vicios, delitos y penas: nuevos rumbos de la historia de la justicia criminal en América Latina", en En la encrucijada: historia, marginalidad y delito en América Latina y los Estados Unidos de Norteamérica (siglos XIX y XX), ed. Jorge Alberto Trujillo Bretón, (Universidad de Guadalajara, 2010), 22.

56 Mauricio, Rojas Gómez; León, Marco A. León. “Control social y construcción de hegemonía en la ciudad de Concepción (Chile), 1860-1900”. Anuario de Estudios Americanos, vol. 70, no 2, (2013), 641. 
ciones precedentes, sino que más bien a resaltar estudios de carácter más localizado. Los artículos sobre el bandidaje que se incluyen, son un avance importante en torno al revisionismo de la teoría de los bandidos sociales de Hobsbawm, específicamente porque las evidencias indican la presencia de "delincuentes audaces y temerarios que sembraron violencia e inseguridad a su paso" 57 .

La última compilación coordinada por este equipo de historiadores, fue dirigida por Eric A. Johnson, Ricardo D. Salvatore y Pieter Spierenburg, profesor de criminología histórica en la Universidad Erasmus de Rotterdam, quien se ha convertido en una figura de autoridad en la historia del crimen en Europa ${ }^{58}$. La compilación se tituló Murder and Violence in Modern Latin America, pero aquí la categoría América Latina no es tratada de manera problemática, de hecho los editores dejan claro desde el inicio que "no se intenta cubrir cada esquina del continente, lo que se intenta es reunir las experiencias de un número de renombrados investigadores, que se enfocan en temas de interés a menudo actuales y fascinantes ${ }^{59}$ ”.

De los nueve artículos incluidos en Murder and Violence in Latin America sólo dos utilizan datos cuantitativos de manera sustantiva: "Judging Violent Crimes: Patterns of Sentencing in Modern Argentina, 1878-1948” de Ricardo Salvatore y "Homicide and Politics in Modern Mexico" de Pablo A. Piccato. Ambos buscan tendencias en sus respectivos campos de estudio: Argentina, desde los registros de la Penitenciaría Nacional entre 1878 y 1948; y México a partir de series históricas recolectadas por el Instituto Nacional de Estadística y Geografía (INEGI), sin embargo no se cuenta aún con un esfuerzo comparativo como el conseguido para Europa donde los hallazgos en investigaciones de tendencias a largo plazo han mostrados excepciones regionales a la tendencia general europea que muestra un decrecimiento continuado de la violencia desde la Edad Media $^{60}$.

57 Salvatore Ricardo D., "De vicios, delitos y penas: nuevos, 27.

58 Johnson, Eric A., Salvatore, Ricardo, Spierenburg, Pieter. Murder and Violence in Modern Latin America. (Bulletin of Latin American Research Book Series, 2013)

59 Salvatore, Ricardo, Johnson, Eric A., Spierenburg, Pieter. Murder and Violence in Modern, 6.

60 Muchembled, Robert. Una historia de la violencia del final de la Edad Media a la actualidad, trad. 
La pregunta en torno a la criminalidad en América Latina ha cambiado sustancialmente, ya no son tan importantes los procesos de tecnificación de las estructuras represivas y la modernización de la ley (positivismo y medicalización del derecho) sino encontrar el sentido de una tendencia regional. Si en Reconstructing Criminality in Latin America se entendía que el hilo unificador de América Latina era su relación con el pasado colonial y el presente neocolonial, en Murder and Violence in Modern Latin America se entiende la región a partir de la globalidad ${ }^{61}$.

No es casualidad que para comprender esta globalidad se adopte la interpretación a partir de la teoría del "proceso civilizatorio" de Norbert Elias. Una de las figuras más representativas de esta tendencia es Pieter Spierenburg, quien ha encontrado eco en diferentes investigadores de quienes destacan el mismo Ricardo D. Salvatore, Carlos Aguirre Rojas, Gina Zabludovsky, Adrián Scribano y Gabriela Vergara Mattar; y los colombianos Víctor Manuel Uribe-Urán y Vera Weiler ${ }^{62}$.

La conclusión de Murder and Violence in Modern Latin America consiste en la consideración teórica acerca de la validez del "proceso civilizatorio" en América Latina, sin embargo más que evaluar la tendencia hacia una pacificación o incremento de la violencia lo que hace Salvatore, en este trabajo, es poner en una perspectiva de comparación los numerosos tipos de violencia que caracterizan la historia democrática y globalizada de América Latina con las ideas de Elias relativas al monopolio de la violencia, la pacificación, las interdependencias sociales y la represión de la agresividad y los impulsos o autocoacción ${ }^{63}$.

Ricardo Salvatore antes que identificar el proceso civilizatorio en América Latina distingue las dificultades para su aplicación al contexto regional. La conclusión de Salvatore es que existen unos "temas eliasianos" que pue-

61 Salvatore, Ricardo, Johnson, Eric A., Spierenburg, Pieter. Murder and Violence in Modern, 62.

62 Melo Flórez, Jairo. "Apuntes sobre la historiografía", 19.

63 Salvatore, Ricardo D., "Conclusion: Violence and the "Civilising Process' in Modern Latin America", en Murder and Violence in Modern Latin America, ed. Eric A. Johnson, Ricardo Donato Salvatore, y Pieter Spierenburg, (The bulletin of Latin American research book series, John : Wiley \& Sons Ltd, 2013), 235. 
den ser estudiados en "clave latinoamericana" como las transformaciones de comportamiento, la monopolización de la violencia, el duelo y los códigos de comportamiento de las élites frente al bajo pueblo y el denominado proceso descivilizatorio que se presenta desde la década de $1960^{64}$.

En definitiva, las similitudes entre En la encrucijada: historia, marginalidad y delito en América Latina y los Estados Unidos de Norteamérica, siglos XIX y XX y Murder and Violence in Modern Latin America son evidentes, ambos son esfuerzos compilatorios que ya no se preocupan por dar explicaciones generales de la violencia y el delito en América Latina sino que de presentar esfuerzos nacionales que permiten al lector hacer comparaciones. En ambos se deja en evidencia la pretensión reciente de introducir el enfoque "eliasiano" en los análisis de la criminalidad latinoamericana, pero la ausencia de cifras confiables, aunado a la aún incipiente revisión historiográfica del desarrollo de las instituciones modernas en las diferentes naciones de América Latina conllevan a que todo estudio con estas características termine siendo otra visión parcial de un proceso que necesita la larga duración para brindar explicaciones -quizás- significativas. En este sentido Lila Caimari, señala que dentro de las grandes dificultades que debe sobrellevar este campo de estudios a la construcción de series largas de datos que permitan ver los fenómenos de la criminalidad en larga duración ${ }^{65}$.

Pues bien, como hemos visto el trabajo historiográfico que se ha desarrollado con mayor continuidad frente al estudio de la cuestión criminal en América Latina, y sus formas de abordaje a través de estudios compilatorios, principalmente enfocados en México y Argentina. Demuestran en parte, la dificultad manifiesta de emprender estudios regionales sobre fenómenos de la criminalidad, dado que los contextos nacionales remiten a ciertas limitantes para exceder de las meras comparaciones entre estados o ciudades. Y las investigaciones sobre la criminalidad aún permanecen dentro de la categoría de estudio de prematuro desarrollo en el debate historiográfico.

64 Salvatore, Ricardo D., “Conclusion: Violence and the 'Civilising Process' in Modern, .256

65 Caimari, Lila. Los historiadores y la "cuestión criminal", 11 
Sin perjuicio de aquello, desde el año 2010 en adelante, los estudios historiográficos sobre la criminalidad en general, han ido abandonado la vinculación dialógica con las ciencias jurídicas y la sociología, especialmente con la criminología. Ahora la tendencia de los estudios ha sido aproximar interpretaciones a los sistemas culturales del fenómeno de la criminalidad, utilizando en algunos casos practicas metodológicas de la antropología histórica y la etnohistoria. Sin embargo, esta vertiente de estudios sobre la criminalidad es aún muy minoritaria, pues los estudios sobre las relaciones de poder entre el Estado y los "criminales" es una de las líneas de mayor producción en este campo de estudios.

Destacan no obstante algunos trabajos que han aumentado el espectro de fuentes operalizables, así como también se ha puesto énfasis en la dimensión cultural y subjetiva del fenómeno de la criminalidad.

Importante es mencionar que en éste tipo giro antropológico en el campo de estudios historiográficos de la criminalidad son varios los historiadores que han transformado evidentemente sus prácticas metodológicas y sus abordajes frente a esta temática durante los últimos años. Lila Caimari, por ejemplo, en Apenas un delincuente. Crimen, castigo y cultura en Argentina. 1880-195566, donde la dimensión cultural juega un rol unificador en el texto, resaltando los aspectos más arraigados en la sociedad argentina frente al desarrollo de un imaginario social sobre el castigo estatal durante la transición del siglo XIX al XX. Caimari demuestra un cambio sustancial en su abordaje a la temática, dado que durante los años anteriores su producción no consideraba esta dimensión cultural, ni las subjetividades propias de la formación de imaginarios sociales, sino más bien, se mantuvo vinculada al Grupo de Estudios de la revista Delito y Sociedad de la Facultad de Ciencias Sociales de la Universidad de Buenos Aires y la Universidad Nacional de Rosario, de manifiesta inclinación por los estudios jurídicos de la cuestión criminal ${ }^{67}$. A su vez, en Chile, Marco Antonio

66 Caimari, Lila. Apenas un delincuente: crimen, castigo y cultura en la Argentina, 1880-1955. En Apenas un delincuente: crimen, castigo y cultura en la Argentina, 1880-1955. (Buenos Aires: Siglo XXI, 2012)

67 Delito y Sociedad. Revista de Ciencias Sociales es una publicación semestral del Programa de Estudios de Control Social (PECOS) que se desarrolla en el Instituto de Investigaciones Gino Germani 
León León - investigador, como ya dijimos de gran valor para la temática en Chile- quien inició sus estudios sobre la criminalidad en la década de 1990 desde una perspectiva socio-jurídica para abordar los sistemas de castigo en el Chile decimonónico, en 2016, dio un giro en la selección del tratamiento de las fuentes utilizadas, publicando un estudio sobre discursos editoriales sobre criminalización, formación de imaginarios punitivos y fotografía criminal. El libro titulado Construyendo a un sujeto criminal. Criminología, criminalidad y sociedad en Chile siglo $X I X$ y $X X^{68}$, ha demostrado un muy buena recepción, siendo a la fecha reseñado y comentado en 9 revistas académicas chilenas y extranjeras de reconocido prestigio. Una de esas reseñas fue publicada por quien habla ${ }^{69}$. El caso de Ignacio Ayala Cordero, es mucho más evidente al plantear la descripción densa como propuesta metodológica para el análisis de los expedientes criminales $^{70}$.

No solo Caimari y León, han demostrado una inclinación e interés por los sistemas culturales en los análisis historiográficos del fenómeno de la criminalidad, respecto a sus trabajos investigativos iniciales. Así también, y creemos que el historiador de la criminalidad que ha sido más certero en su esfuerzo por vincular la Historia Cultural con el campo de estudios sobre la criminalidad ha sido el peruano Carlos Aguirre, que como vimos es uno de los historiadores más constante en los esfuerzos por abordar el fenómeno de la criminalidad en perspectiva latinoaméricana. Con su reciente estudio sobre "la prisión y la ciudad letrada", ha demostrado y manifestado su intención de dirigir los estudios sobre los sistemas de casti-

y de la cátedra "Delito y Sociedad: sociología del sistema penal", ambos de la Facultad de Ciencias Sociales. Universidad de Buenos Aires, República Argentina. Es editada desde 1992 y puede ser visita en línea en: https://bibliotecavirtual.unl.edu.ar/ojs/index.php/DelitoYSociedad/about

68 León, Marco Antonio León. Construyendo un sujeto criminal: criminología, criminalidad y sociedad en Chile: siglos XIX y XX. (Santiago: Editorial Universitaria, 2015)

69 Castro Valdebenito, Hugo J. Marco Antonio León León. Construyendo un sujeto criminal. Criminología, criminalidad y sociedad en Chile. Siglos XIX y XX. Santiago: Centro de Investigaciones Diego Barros Arana-DIBAM-Editorial Universitaria, 2016. Historia Caribe, vol. 13, no 32, (2018) http://investigaciones.uniatlantico.edu.co/revistas/index.php/Historia_Caribe/article/download $/ 1903 / 2193$

70 Ayala Cordero, Ignacio. Criminales y Cómplices. Práctica criminal, redes sociales y reproducción de marginalidad en Santiago, Valparaíso y Buenos Aires, 1890-1910.. (Tesis Doctoral. Tesis para optar al grado de Magíster en Historia con mención en Historia de América, U. de Chile, Santiago. 2010) 
gos estatales hacia la observación de la Historia Cultual ${ }^{71}$. Es probable que el abordaje histórico de la producción de una cultura escrita y trastocada desde la experiencia de encierro y tortura en Perú sea limitada en tanto su concepto de cultura no profundiza en la cultura interna carcelaria, en lo que algunos autores de la sociología jurídica han denominado el "mundo de los presos", compuesto por una compleja red de sistemas subcultuales que incluyen lenguajes propios, códigos de conducta y honor, imaginarios colectivos y prácticas basadas en costumbres tradicionales del contexto de encierro. Aguirre busca examinar el impacto de dicha producción literaria que en lo medular se concentra en la producción de una textualidad político-intelectual limeña encarcelada. El estudio es sin duda un modelo de abordaje bastante interesante para pensar en replicarlo en otro país, no obstante, conviene insistir en la necesidad de profundizar en los diferentes sistemas culturales del contexto de encierro carcelario para así comprender mejor los elementos necesarios en un abordaje cultural de las prisiones.

Salvatore también, al igual que los historiadores anteriormente señalados, ha mostrado una inclinación por los estudios culturales de la criminalidad en sus últimos trabajos publicados, con respecto a la orientación más hacia apegada al derecho en sus trabajos iniciales en los años ochentas y noven$\operatorname{tas}^{72}$.

En síntesis, el desarrollo de la historiografía de la criminalidad en América Latina y desde América Latina como escenario de pesquisa ha deambulado por dos vertientes problemáticas. Primero, a razón de los estudios iniciales de corte jurídico sobre América Latina en la década de 1980, que promocionaron un período de abordajes desde las ciencias penales y sociales. Aquellos estudios - en su mayoría comparados - se preocuparon en denunciar los abusos de los sistemas de castigo estatal en tiempos de dictaduras, apropiándose, principalmente, de los planteamientos de la criminología crítica italiana que en consecuencia formaron la base de la cri-

71 Aguirre, Carlos. La cárcel y la ciudad letrada: hacia una historia cultural de la prisión en el Perú del siglo veinte. Delincuentes, policías y justicias. América Latina, siglos XIX y XX, (Santiago: UAH, 2015)

72 Ver Salvatore, Ricardo Donato. Subalternos, derechos y justicia penal: ensayos de historia social y cultural argentina 1829-1940. (Gedisa Editorial, 2013) 
minología crítica latinoamericana poscolonial. Ya vimos los ejemplos del impacto de los textos de José Rico y Rosa del Olmo en la década de 1980. Esta vertiente de estudios además de ser la primera en observar a América Latina como un conjunto problemático para el estudio de la criminalidad, priorizó a la Historia como disciplina auxiliar, dando lugar a una relación dialógica entre la historiografía y los estudios socio-jurídicos de la criminalidad.

En las décadas que siguen a este período la condición de disciplina auxiliar que había adquirido la historia dentro del campo de estudios de la criminalidad se revierte y la historiografía de la criminalidad inicia una importante producción, principalmente en Estados Unidos, Inglaterra, México y Argentina. Los trabajos de los historiadores latinoamericanos de la criminalidad se concentraron en aplicar modelos interpretativos a los contextos nacionales, utilizando varias ciencias como auxiliares metodológicos e incluso teóricos para efectuar las interpelaciones al pasado social del fenómeno criminológico. Pocos esfuerzos se encuentran desde una investigación histórica individual que abarque el fenómeno a nivel latinoamericano pese a las compilaciones iniciadas a principios de la década de 1990 por la gran parte de los historiador que hemos mencionado en este apartado, adscritos hoy a la Red de Historiadores e Historiadoras del Delito en Las Américas. Estas compilaciones atendían a estudios de casos nacionales, que buscaron ser comprendidos en lectura comparativa. La naturaleza de los abordajes, si bien eran historiográficos en su planteamiento, el diálogo metodológico era mayormente con las ciencias penales y la sociología. En este período el campo de estudios sobre la criminalidad se perfiló como tal y las investigaciones sobre delincuentes, policías, prostitutas, vagabundos, bandidaje, prisiones, en fin, sobre variados ámbitos y actores de la criminalidad que proliferaron en varios países.

Durante los últimos años, las trayectorias historiográficas de varios historiadores de la Red de Historiadores e Historiadoras del Delito en Las Américas, ha ido manifestando un interés por el estudio de los sistemas culturales representándolo en diversas formas y abordajes etnohistóricos. En este sentido, es importante visibilizar las distintas iniciativas, centros de 
estudios especializados y revistas sobre la historia de la criminalidad en Latinoamérica para observar y ponderar los grados de consenso o debate que se presentan en las diversas experiencias historiográficas latinoamericanas. En especial respecto al giro cultural que se viene dando desde $2011^{73}$, en este campo de estudios.

\section{Circulación del debate historiográfico sobre la CRIMinalidad EN LATINOAMÉRICA}

Tal vez una de las conferencias más importantes sobre debates en torno a los estudios sobre el delito, la justicia y el castigo en perspectiva latinoamericana fue el congreso titulado "Contested Terrains of Law, Justice, and Repression in Latin American History" llevado a cabo en la Universidad de Yale en abril de 1997, de cuyas conferencias se nutrieron los editores de las dos primeras compilaciones Reconstructing Criminality in Latin America y Crime and Punishment in Latin America, ya presentadas anteriormente. No obstante un año antes, Eduardo Zimmermann con el apoyo del Institute of Latin American Studies (ILAS) había convocado una reunión en la Universidad de Londres dónde trataron temas de historia de las instituciones judiciales en América Latina. El taller se denominó "The History of Justice in Ninetheenth-Century Latin America" y de éste surgió el libro compilatorio Judicial Insititutions in Ninethennth-Century Latin America ${ }^{74}$. Ambas reuniones son importantes puesto que dieron paso a la vertiente principal de estudios de la historia del delito y la justicia en la primera década del siglo XXI, decantándose algunos por la nueva historia del derecho y otros por una historia más cercana -como hemos dicho- a las investigaciones sobre la historia del delito, la justicia penal y las instituciones de control social.

En América Latina se llevaron a cabo algunas reuniones que también revisten de trascendencia a nivel local a pesar que su ámbito era latinoamericano. El más conocido fue el "Seminario sobre Justicia y Sociedad en

73 Especialmente con la formación de la Red de Historiadores e Historiadoras del Delito en Las Américas.

74 Zimmermann, Eduardo A. (ed.). Judicial Institutions in Nineteenth-Century Latin America. (London: Institute of Latin American Studies, 1999) 
América Latina" organizado por el Centro de Estudios Latinoamericanos de la Universidad Nacional de San Martín llevado a cabo en Buenos Aires en el año 2004. Si bien el seminario no fue una convocatoria para la historia del crimen y el delito sí permitió la reunión de varios especialistas enfrentados a problemas de investigación que trascendían el plano meramente institucional y legislativo de la historia de la justicia y del delito.

Esta reunión dio pie para considerar la necesidad de conformar una red de investigadores de la historia del delito la cual se logró concretar en Guadalajara aprovechando el primer "Coloquio Internacional. Historia, Marginalidad y Delito en América Latina”, que se llevó a cabo en la Universidad de Guadalajara en mayo de 2011. El impulso sería hecho realidad gracias a la propuesta editorial que culminó en el primer libro compilatorio en español sobre la criminalidad en América Latina - En la encrucijada: historia, marginalidad y delito en América Latina y los Estados Unidos de Norteamérica (siglos $X I X$ y $X X$ ) - del cual se trató anteriormente. Se denominó a esta nueva la red como "Red de Historiadores e Historiadoras del Delito en las Américas” (REDHHDA), su carácter es multidisciplinario y su objetivo es la innovación metodológica y la revisión historiográfica en torno a la historia de la criminalidad en América Latina ${ }^{75}$.

En total han realizado cinco encuentros, dos en Guadalajara en 2011 y 2012 y uno en Santiago en 2013, y otro en Rio de Janeiro en 2016 desde el cual surgío el libro compilatorio del historiador chileno Daniel Palma titulado Delincuentes, policías y justicias en América Latina ${ }^{76}$. El último encuentro se realizó en la Universidad de La República en Montevideo en marzo de $2018^{77}$.

Obviamente estos no son los únicos eventos que abordan el tema de la criminalidad y la justicia en América Latina ni tampoco todos los autores

75 La REDHHDA: Acta constitutiva de la red de historiadores e historiadoras del delito en las Américas", Red de Historiadores e Historiadoras del Delito en Las Américas, consultado el 07/07/2018 en: http://redhhda.blogspot.mx/p/blog-page_16.html.

76 Palma, Daniel. Delincuentes, policías y justicias: América Latina, 34

77 Ver notas del Simposio en: http://redhhda.blogspot.com/2017/04/v-simposio-internacional-de-la-redhhda.html 
interesado en la temática, reseñarlos aquí sería una tarea imposible, pues como señala León León en la introducción de su tesis doctoral, "este campo de estudios no goza de prestigio por lo que los fondos son escasos para financiar proyectos sobre la temática. Esto provoca un desarrollo fragmentado y localizado de historiadores interesados por la cuestión criminal" ${ }^{\prime 78}$.

En este sentido las revistas especializadas son espacios de encuentro para historiadores de la criminalidad, pues siguen siendo un lugar privilegiado para la publicación de los trabajos relacionados con el crimen y la justicia en América Latina, aunque predominan las publicaciones dispersas en revistas disciplinares. Hacer un recuento de todos ellas es una tarea que desborda el objetivo de este trabajo, pero vale la pena hacer mención a la larga tradición de la Revista Delito y Sociedad de la Universidad Nacional del Litoral, por su larga historia y su labor como canal de introducción de las ideas de la criminología critica italiana y latinoamericana, al igual que la revista mexicana Clio y Crimen editada por el Centro de Historia del Crimen de Durango. Así también, señalar que no hace mucho tiempo se fundó en Tucumán la primera revista académica exclusivamente para investigaciones historiográficas sobre los sistemas de presidio: la Revista Historia de las Prisiones es editada por Instituto de Investigaciones Históricas Leoni Pinto (INIHLEP) de la Universidad Nacional de Tucumán ${ }^{79}$. En Chile, los estudio sobre la temática pueden encontrase dispersos en distintas revistas de historia, pero en términos de especialización en estudios historiográficos sobre criminalidad y las justicias, el Grupo Historia y Justicia es el que se ha posicionado como un centro de debate altamente especializado y concreto sobre la temática, en especial a través de su Revista HyJ y los Seminarios Permanentes que enfatizan en el binomio historia $\mathrm{y}$ justicia a nivel nacional tanto como internacional ${ }^{80}$.

78 León León, Marco Antonio. Encierro y corrección. La configuración de un sistema de prisiones en Chile (1810-1911). (Disertación PhD. en Historia. Pontifica Universidad Católica de Chile, 2003)

79 La Revista de Historia de las Prisiones pretende dar cuenta de este horizonte, en curso de renovación. La Revista cuenta con el aval y es editada por el Instituto de Investigaciones Históricas Leoni Pinto (INIHLEP) de la Universidad Nacional de Tucumán. Es un proyecto federal, cuya dirección se sitúa en las provincias de Córdoba y Buenos Aires y cuyo sello editorial y parte del equipo de redacción se radica en la provincia de Tucumán. Además posee una Biblioteca Virtual de Historia de la Penalidad en : http://www.revistadeprisiones.com/

80 El Grupo Historia y Justicia funciona activamente desde fines del 2010 con base en Chile. Está 


\section{Conclusiones}

$¿$ Es posible hablar de una historia del crimen y del delito de América Latina? Es evidente que desde el momento que los enfoques de Thompson, Hobsbawm y Foucault alcanzan a los investigadores latinoamericanos se abrió la posibilidad de construir una historia de la criminalidad latinoamericana. Esta sin embargo se produce desde tres centros principales: Estados Unidos, México y Argentina. En Estados Unidos ha sido liderada por historiadores latinoamericanos que investigan desde las universidades norteamericanas, específicamente desde los centros y facultades de historia de América Latina. En México el liderazgo lo llevan autores como Pablo Piccato, Elisa Speckman y Jorge Alberto Trujillo, mientras en Argentina el trabajo de Ricardo D. Salvatore y Lila Caimari han sido la vanguardia de este ámbito de estudio historiográfico.

Se observa un cambio metodológico y de enfoque a lo largo de la trayectoria de este campo de estudios. En un comienzo el interés fue comprender los factores comunes de la criminalidad latinoamericana a partir de su interpretación histórica como un mundo resultado de los procesos de colonización y neocolonización, desde hace unos años se abandonó en parte la perspectiva latinoamericana para entender la región en términos del conjunto de países interconectados con el mundo globalizado, por ello teorías de mayor amplitud como el "proceso civilizatorio" de Norbert Elías encuentran cabida en perspectivas comparativas aún mayores. Se entiende que la criminalidad y la violencia en América Latina es particular de la región, pero lo que se está intentando comprender es el por qué es tan persistente a pesar de los esfuerzos modernizadores de las élites nacionales.

Sin embargo no se puede considerar que este ámbito de estudios haya alcanzado su madurez. Los esfuerzos de los historiadores de la criminalidad siguen siendo dispersos tanto geográfica como metodológicamente, las

formado por miembros activos que participan de las reuniones anuales y de las actividades asociadas al grupo. Su programa se organiza anualmente con actividades coordinadas e implementadas por distintas comisiones y responsables. Puede ser visitado en su website en: http:/ historiayjusticia.org/ 
interpretaciones siguen estando limitadas en buena medida a preconcepciones importadas desde el ámbito europeo o análisis demasiado limitados a nivel regional-nacional que impactan en una repetición de observaciones que sin embargo no logran acumular un discurso coherente a nivel regional. A pesar de lo anterior, los historiadores de la criminalidad y la justicia están conformando tímidamente redes de conocimiento que han dado algunos frutos en términos de libros y conferencias, el siguiente paso consistiría en promover el desarrollo de una publicación científica que reuniera los trabajos producidos a nivel latinoamericano. Además, un esfuerzo por la traducción de obras publicadas en ingles cumpliría un rol potenciador, como sin duda lo logró la traducción de los trabajos de Thompson, Hobsbawm y Foucault al español en la década de los ochentas en México y Argentina por Siglo XXI, y que ha jugado un rol fundamental en la promoción de esta temática.

En lo nos concierne, hemos abordado la temática desde la pesquisa empírica de archivos internos de los centros de presidio chilenos, en especial sobre la Cárcel Penitenciaria de Santiago en Modelos, tendencias y cotidianidades en los inicios de la cárcel penitenciaria de Santiago de Chile, 1843-186081, donde nos aproximamos a prácticas de alimentación, salubridad, vestimenta y tratamiento penitenciario en los primeros años de ejecución de la reforma al sistema de castigos penales. También hemos querido ingresar a las cotidianeidades del encierro político decimonónico a través de la puesta en valor de archivos documentales de la Superintendencia de Penitenciaria en el Sumario por fuga del reo político Juan Antonio Pando en la Cárcel Penitenciaria de Santiago en $1859^{82}$, además de entender el desarrollo de los sistemas de justica regional en Historia de las justicias latinoamericanas durante los siglos XVI y XIX ${ }^{83}$. Estas aproximaciones a las relaciones de poder derivadas de las experiencias de encierro derivan

81 Castro Valdebenito, Hugo Jose; SÁNCHEZ, Alessandro Monteverde; SAAVEDRA, Juan. "Modelos, tendencias y cotidianidades en los inicios de la cárcel penitenciaria de Santiago de Chile, 18431860”. Diálogos: Revista electrónica de historia, vol. 19, no 1, (2018), 69-101.

82 Castro Valdebenito, Hugo J. "Sumario por fuga del reo político Juan Antonio Pando en la Cárcel Penitenciaria de Santiago en 1859". Archivo Nacional Histórico de Chile, Fondo Ministerio de Justicia, Culto e Instrucción Pública, volumen 247, número 139. Revista Historia y Justicia, no 9. (2017)

83 Castro Valdebenito, Hugo José. "Historia de las justicias latinoamericanas durante los siglos XVI y XIX”. Revista de História, USP, no 176, (2017) 01-06. 
de la investigación que hemos publicado en el libro titulado Conspiraciones, motines y sedición en Aconcagua. 1850-185184, donde el corpus documental de la pesquisa involucró una aproximación hermenéutica a los archivos judiciales por casos de enjuiciamientos penales a personeros políticos miembros de una oposición política liberal, insurrectos, amotinados y participantes de las sublevaciones locales de dicho período.

En conclusión, el campo de estudios historiográficos sobre la criminalidad - como hemos visto- ha transitado por una trayectoria de diálogos disciplinares, apropiaciones teórico-metodológicas y debates dirigidos desde puntos de enunciación ajenos a Latinoamérica. Lo que sin embargo, no disminuye el valor de las iniciativas regionales en español, sobre todo por lo que se está realizando a través de la Red de Historiadores e Historiadoras del Delito en las Américas y las diversas revistas y congresos especializados. Sin perjuicio de toda la trayectoria historiográfica de la cuestión criminal en América Latina, nos parece relevante el giro cultural que se ha ido generando en los últimos años a lo largo de Latinoamérica respecto a los abordajes de los historiadores de la criminalidad. Este enfoque es sin duda un abordaje interesante y mucho más complejo en términos interpretativos dadas las dificultades para acceder y observar -etnográficamente por ejemplo- los espacios de presidio, y más aún cuando se pretende observar e interpelar en perspectiva historia.

\section{Bibliografía}

Aguirre Carlos y Salvatore Ricardo D. "Writing the History of Law, Crime, and Punishment in Latin America", en Crime and punishment in Latin America: law and society since late colonial times, ed. Ricardo Donato Salvatore, Carlos Aguirre, y Eric A. Johnson, (Duke University Press, 2001)

Aguirre, Carlos A.; Buffington, Robert (ed.). Reconstructing Criminality in Latin America. (Rowman \& Littlefield Publishers, 2001)

Aguirre, Carlos. "Cárcel y sociedad en América Latina". Historia social urbana: Espacios y flujos, en Ed. Eduardo Kingman, (2009)

84 Castro, Hugo, Monteverde, A. Conspiraciones, motines y sedición en Aconcagua. 1850-1851. (Valparaíso, Ediciones Universidad de Playa Ancha, 2016). 
Aguirre, Carlos. La cárcel y la ciudad letrada: hacia una historia cultural de la prisión en el Perú del siglo veinte. Delincuentes, policías y justicias. América Latina, siglos XIX y XX, (Santiago: UAH, 2015).

Aguirre, Carlos y Walker, Charles (ed.). Bandoleros, abigeos y montoneros: criminalidad y violencia en el Perú, siglos XVIII-XX. (Lima: Instituto de Apoyo Agrario, 1990);

Albornoz Vásquez, María Eugenia. "Seguir un delito a lo largo del tiempo: Interrogaciones al cuerpo documental de pleitos judiciales por injuria en Chile, Siglos XVIII y XIX.” Revista de Historia Social y de las Mentalidades, Vol. 10. N² (2006): 195-226.

Argouse, Aude. "Prueba, información y papeles. Hacia una plena inclusión del escribano y de sus agencias en la historia de la justicia en Hispanoamérica (Chile, siglos XVII-XVIII)". Revista Historia y Justicia, no 8, (2017), 97-137.

Aufderheide, Patricia. Order and Violence: Social Deviance and Social Control in Brazil (1780-1840), (Ph.D. dissertation, University of Minnesota, Minneapolis, 1976)

Ayala Cordero, Ignacio. Criminales y Cómplices. Práctica criminal, redes sociales y reproducción de marginalidad en Santiago, Valparaíso y Buenos Aires, 1890-1910. (Tesis Doctoral. Tesis para optar al grado de Magíster en Historia con mención en Historia de América, U. de Chile, Santiago. 2010)

Beccaria, Cesare. Tratado de los delitos y de las penas. En casa de Rosa, (Paris: Librero, 1828)

Bentham, Jeremy. Panopticon: or, The inspection-house. Containing the idea of a new principle of construction applicable to any sort of establishment, in which persons of any description are to be kept under inspection, etc. (Dublin: Thomas Byrne, 1791)

Bergalli, Roberto, et al. Control social punitivo. Sistema penal e instancias de aplicación (policía, jurisdicción y cárcel), Barcelona: Bosch, 1996) Caimari, Lila. "Los historiadores y la "cuestión criminal" en América Latina. Notas para un estado de la cuestión”. Revista de Prisiones, No2, (2016)

Caimari, Lila. Apenas un delincuente: crimen, castigo y cultura en la Argentina, 1880-1955. En Apenas un delincuente: crimen, castigo y 
cultura en la Argentina, 1880-1955. (Buenos Aires: Siglo XXI, 2012) Castro Valdebenito, Hugo J. "Sumario por fuga del reo político Juan Antonio Pando en la Cárcel Penitenciaria de Santiago en 1859". Archivo Nacional Histórico de Chile, Fondo Ministerio de Justicia, Culto e Instrucción Pública, volumen 247, número 139. Revista Historia y Justicia, no 9. (2017)

Castro Valdebenito, Hugo J. y León León, Marco Antonio. Construyendo un sujeto criminal. Criminología, criminalidad y sociedad en Chile. Siglos XIX y XX. Santiago: Centro de Investigaciones Diego Barros Arana-DIBAM-Editorial Universitaria, 2016. Historia Caribe, vol. 13, no 32, (2018) http://investigaciones.uniatlantico.edu.co/revistas/index.php/Historia_Caribe/article/download/1903/2193

Castro Valdebenito, Hugo Jose; Sánchez, Alessandro y Monteverde Saavedra, Juan. "Modelos, tendencias y cotidianidades en los inicios de la cárcel penitenciaria de Santiago de Chile, 1843-1860”. Diálogos: Revista electrónica de historia, vol. 19, no 1, (2018), 69-101.

Castro Valdebenito, Hugo José. "Historia de las justicias latinoamericanas durante los siglos XVI y XIX”. Revista de História, USP, no 176, (2017) 01-06.

Castro Valdebenito y Hugo José; Sánchez, Alessandro y Monteverde Saavedra, Juan. "Modelos, tendencias y cotidianidades en los inicios de la cárcel penitenciaria de Santiago de Chile, 1843-1860”. Diálogos: Revista electrónica de historia, vol. 19, no 1, (2018), 69-101.

Castro, Hugo y Monteverde, A. Conspiraciones, motines y sedición en Aconcagua. 1850-1851. (Valparaíso, Ediciones Universidad de Playa Ancha, 2016).

Del Olmo, Rosa. América Latina y su criminología (México: Siglo XXI, 4ta ed. 1999)

Del Olmo, Rosa. América Latina y su criminología. (México: Siglo XXI, 1ra ed. 1981)

Elias, Norbert. El proceso civilizatorio. (Rio de Janeiro: Jorge Zahar, 1990) Fausto, Boris. Crime e cotidiano: a criminalidade em São Paulo, 1880-1924. (Sao Paulo: Edusp, 1984)

Fernández Labbé, Marcos. "Relatos de precariedad y encierro: la cárcel rural en el Chile de la segunda mitad del siglo XIX". Contribuciones científicas y tecnológicas, vol. 26, (1998) 
Fernández Labbé, Marcos. Prisión común, imaginario social e identidad: Chile, 1870-1920. (Santiago: Dirección de Biblioteca Archivos y Museos, 2003)

Foucault, Michel. Vigilar y castigar: nacimiento de la prisión. (Buenos Aires: Siglo XXI, 1975)

Gargarella, Roberto. Los fundamentos legales de la desigualdad: el constitucionalismo en América (1776-1860). (Madrid: Siglo XXI, 2005)

Hay, Douglas. "Law and Society in Comparative Perspective", en Crime and punishment in Latin America: law and society since late colonial times, ed. Ricardo Donato Salvatore, Carlos Aguirre, y Gilbert M. Joseph (Duke University Press, 2001)

Hay, Douglas. "Law and Society in Comparative Perspective", en Crime and punishment in Latin America: law and society since late colonial times, ed. Ricardo Donato Salvatore, Carlos Aguirre, y Gilbert M. Joseph (Duke University Press, 2001)

Johnson, Eric A.; Salvatore, Ricardo y Spierenburg, Pieter. Murder and Violence in Modern Latin America. (Bulletin of Latin American Research Book Series, 2013)

León León, Marco Antonio. Encierro y corrección. La configuración de un sistema de prisiones en Chile (1810-1911). (Disertación PhD. en Historia. Pontifica Universidad Católica de Chile, 2003)

León, Marco Antonio. Construyendo un sujeto criminal: criminología, criminalidad y sociedad en Chile: siglos XIX y XX. (Santiago: Editorial Universitaria, 2015)

León, Marco Antonio León. Encierro y corrección: la configuración de un sistema de prisiones en Chile: 1800-1911. (Santiago: Universidad Central de Chile, Facultad de Ciencias Jurídicas y Sociales, 2003).

Linebaugh, Peter, et al. Albion's fatal tree: crime and society in eighteenth-century (London: Allen Lane, 1975)

Lozoya, Ivette. Delincuentes, bandoleros y montoneros: Violencia social en el espacio rural chileno (1850-1870). (Santiago: LOM Ediciones, 2014)

306 Mauricio, Rojas Gómez y León, Marco A. “Control social y construcción de hegemonía en la ciudad de Concepción (Chile), 1860-1900”. Anuario de Estudios Americanos, vol. 70, no 2, (2013) 
Melo Flórez, Jairo. "Apuntes sobre la historiografía del crimen y la justicia penal de América Latina”. Historia, crimen y justicia, (2015), https://hccj.hypotheses.org/2

Melossi, Darío y Pavarini, Massimo. Cárcel y fábrica: los orígenes del sistema penitenciario (siglos XVI-XIX). (México: Siglo XXI, 1985)

Muchembled, Robert. Una historia de la violencia del final de la Edad Media a la actualidad, trad. Núria (Petit Fonserè, Paidós, 2010)

Pavarini, Massimo. Control y dominación: teorías criminológicas burguesas y proyecto hegemónico. (México: Siglo XXI, 1983)

Picó, Fernando. El día menos pensado: historia de los presidiarios en Puerto Rico, 1793-1993. (San Juan: Ediciones Huracán, 1994)

Rico, José M. Crimen y justicia en América Latina. (México: Siglo XXI, 1ra ed., 1977)

Rico, José M. Justicia penal y transición democrática en América Latina. (México: Siglo XXI, 5ta ed., 1997)

Rohlfes, Laurence John. Police and Penal Correction in Mexico City, 18761911: A Study of Order and Progress in Porfirian Mexico. 1984. (Dissertation, Tulane University, New Orleans, 1983)

Salvatore Ricardo D. "De vicios, delitos y penas: nuevos rumbos de la historia de la justicia criminal en América Latina”, en En la encrucijada: historia, marginalidad y delito en América Latina y los Estados Unidos de Norteamérica (siglos XIX y XX), ed. Jorge Alberto Trujillo Bretón, (Universidad de Guadalajara, 2010)

Salvatore Ricardo D.; Aguirre, Carlos y Joseph Gilbert M., eds., Crime and punishment in Latin America: law and society since late colonial times, (Duke University Press, 2001)

Salvatore, Ricardo D. "Criminal justice history in Latin America: promising notes”. Crime, Histoire \& Sociétés/Crime, History \& Societies, vol. 2, no 2, (1998)

Salvatore, Ricardo D. “Conclusion: Violence and the 'Civilising Process' in Modern Latin America”, en Murder and Violence in Modern Latin America, ed. Eric A. Johnson, Ricardo Donato Salvatore, y Pieter Spierenburg, (The bulletin of Latin American research book series, John : Wiley \& Sons Ltd, 2013)

Salvatore, Ricardo D. y Aguirre, Carlos (ed.). The birth of the penitentiary 
in Latin America: essays on criminology, prison reform, and social control, 1830-1940. (Texas: University of Texas Press, 1996)

Salvatore, Ricardo D. y Aguirre, Carlos. Revisitando El nacimiento de la penitenciaría en América Latina veinte años después. Revista de Prisiones, $N^{\circ} 4$, (2017)

Salvatore, Ricardo Donato. Subalternos, derechos y justicia penal: ensayos de historia social y cultural argentina 1829-1940. (Gedisa Editorial, 2013)

Sozzo, Máximo. Policía, violencia, democracia: ensayos sociológicos. (Santa Fe: U.Nac. del Litoral, 2005)

Trujillo Breton, Jorge Alberto, et al. En la encrucijada: historia, marginalidad y delito en America Latina y los Estados Unidos de Norteamerica (siglos XIX y XX). (Guadalajara: Universidad de Guadalajara, 2010)

Vallejos, Julio Pinto, et al. El orden y el bajo pueblo: los regímenes de Portales y Rosas frente al mundo popular, 1829-1852. (Santiago: LOM Ediciones, 2015).

Walker Charles F. en Crime and punishment in Latin America: law and society since late colonial times, ed. Ricardo Donato Salvatore, Carlos Aguirre, y Eric A. Johnson, (Duke University Press, 2001)

Zaffaroni, Eugenio Raúl. Sistemas penales y derechos humanos en América Latina: documento final del programa de investigación. Informe final. (Buenos Aires: Ediciones Depalma, 1986)

Zimmermann, Eduardo A. (ed.). Judicial Institutions in Nineteenth-Century Latin America. (London: Institute of Latin American Studies, 1999)

Para citar este artículo: Castro Valdebenito, Hugo José. "Historiografía de la criminalidad en América Latina. Una trayectoria de diálogos disciplinares y debates regionales", Historia Caribe, Vol. XIV No. 35 (Julio-Diciembre 2019): 271-308. DOI: http://dx.doi.org/10.15648/hc.35.2019.10 